\title{
Empirical Issues And Examples: Growth Theory
}

Elif Oznur Kan, (Email: elifoznurkan@ cankaya.edu.tr), Cankaya University

Tolga Omay, (Email: omayt@yahoo.com), Cankaya University

\begin{abstract}
This paper deals with the growth literature. In particular our fundamental concern in this paper will be the empirical studies which are held nowadays. For this purpose, we will mainly base our study on a recent paper called as "The New Growth Evidence" which was written out by J. Temple (2000) who gives a very detailed discussion of the empirical issues concerning the growth literature. In this work we will not only be giving his paper's brief summary but also will be pointing out the borders of growth theory with a number of specific examples of empirical studies in growth literature. In this respect, we will organize three types of empirical analysis which are achieved by different estimation procedures. In the first example, we will deal with cross country evidence in which we aim to point out the growth differences between developed and underdeveloped countries. In order to show these differences we will gather data about fifty countries and make cross section analysis in between. We will then use Chow methodology to pinpoint the structural break between developed and underdeveloped countries. In the second example, we will provide a time series analysis of one country, in which we intend to find out whether a country's productivity level does or does not affect the GNP growth rate. Last and the third example will be given from a panel data analysis, in which we will take the same sample countries as of the cross section analysis. The rationale will be to pool all the countries at first and observe the existence of any regularity and later to apply panel data analysis to each group of country -namely developed and underdeveloped- by the help of cross section analysis. The purpose of this empirical study is to show robustness of the empirical regularities in the homogeneous type countries. In conclusion, the paper will give brief summaries of theoretical and empirical issues which will be covering the boundaries of discussions and more importantly covering all the main types of empirical studies.
\end{abstract}

\section{INTRODUCTION}

ome of the Classical School Thinker have touched on several topics related to the modern growth theory. Briefly, their arguments embraced fundamental dynamic equilibrium approaches in perfect competition environments, the role of diminishing returns and its influence on physical capital accumulation and human capital, the effects of population growth on capital per capita, technological advances which led to the development of specialization and evolution of new methods of production, and finally the technological advantages brought about by monopolistic power.

This fundamental framework of neoclassical tradition has been considered until the 1950s. After the new evolutions of 1950s, the principal concepts of the neoclassical tradition such as total capital stock, total production function and utility function showing the representative individual have started to being used in the growth literature. Besides, modern tools such as dynamic optimization and differential equations have also been utilized.

Chronologically, the very first outstanding work in growth theory is considered to be the paper written out by Ramsey in 1928. This paper has gone well beyond its epoch and gained a significant recognition in the literature. In his study, Ramsey has undertaken the inter-temporal optimization of an individual through the use of a utility function that can be divided inter-temporarily. However, these contributions of Ramsey could not be realized until the 1960s. 
Between Ramsey and the end of 1950s Harrod (1939) and Domar (1946) tried to apply the Keynesian analysis to the growth theory. By making small substitutions between the inputs in the production function, they intended to show that the capitalist system not unstable. Although their papers were well appreciated by the economists of the post Great Depression era, this approach is not considered in current literature.

Following these periods, Solow and Swan (1956) developed very similar models without knowing each others. This model is considered to be the most important contribution to the growth literature. It mainly involves neoclassical production function, constant returns to scale, diminishing returns for each input and the positive substitution rate between inputs. This production function is combined with the constant savings rate to achieve a simple general equilibrium model.

The most significant empirical finding from this model is that it takes into account of the conditional convergence function. The main principle of conditional convergence is that in the long run or static situation equilibrium, growth rate increases as GNP per capita is decreased. The underlying reason beneath this result is that the production function in this model is formed according to the law of diminishing returns. If the capital per worker rate in an economy is considerably below the long run equilibrium, it will yield a higher returns to capital rate and hence a higher growth rate. This high growth rate will cause the underdeveloped countries to conditionally catch up with the developed countries, in other words it will yield convergence. This convergence is conditional since that steady state capital and the output per worker depends on the savings rate, population growth rate and the position of the production function in the Solow-Swan model. These conditions can change from an economy to another. Recent empirical studies have shown that inter country differences such as government policies and initial human capital, should be added to these works.

Another presumption of the Solow-Swan model is that growth per capita cuts off when technological development stops. This result stems out from the fact that they assume diminishing returns to capital. This presumption which is also found in the Malthus and Ricardo's works has not proven to be accurate since that growth per capita has been going on for centuries.

The deficiency of the model was also noticed by the neoclassical economists in the 1950s and 1960s. They attributed the reason underneath to taking technological developments as external. They tried to solve this problem by adding the technological development to the model through long run constant growth per capita while still preserving the conditional convergence. However in the long run what determines growth per capita is the technological development which is mentioned as external in the model. This long run growth model has led to an undesirable situation which indeed occurred later.

After the Solow-Swan model Cass and Koopmans(1965) and Diamond models entered into the growth literature. Cass-Koopmans adapted Ramsey's analysis to the neoclassical growth model. By this adaptation, savings rate has been accounted as internal in the model. This development resulted in richer transitional dynamic models where conditional convergence presumption still holds. Besides, internal savings prevents growth per capita to be caused by external technological developments in the long run.

Cass-Koopmans neoclassical growth model shows consistency with the decentralized competitive structure which ensures that productive factors of worker and capital are valued according to their marginal products. This decentralized conclusion is a pareto optimal.

Another progress and innovation in the later models is that technological development is taken as an endogenous variable. However, this can only be possible by removing standard neoclassical assumptions so as to internalize technology and replace them with other assumptions. Technological development involves arousal of new ideas which are non-rival. Being non-rival, these ideas cause the state of public goods to be investigated. In data technology this depends on the state of information. Thus rival factors of production such as labor, capital and land should be considered under constant returns to scale assumption. If started with non-rival input assumption, increasing returns to scale will prevail which will then prevent building a model in perfect competition environment. 
Arrow(1962) and Sheshinski (1967) built a model which indicates that production and investment produces increasing returns to scale. This model was mainly formed on the learning by doing concept. In this model, an innovation which is found by an individual spreads to the rest of the economy straight off. This instantaneous spread stems out from the fact that information is non-rival. Romer (1986) came up with a new equilibrium model in which he added the technological development without violating the competitive model structure. However, the growth he came up with was not a pareto optimal which indicated that competitive structure was violated in this model.

The investigation of these types of models rendered it compulsory to use neoclassical growth models in imperfect competitive environments as well. This new trend of growth models continued until Romer's works that he did between 1987 and 1990.

Cass-Koopmans completed the fundamental neoclassical growth model. Later, growth models were undertaken technically and their relation with empirical works was terminated. In the early 1970s, this fact caused growth theory to be ignored. At this time, short run macroeconomic fluctuations became the popular research topics.

In the late 1980s economic growth theory of Romer (1986) and Lucas (1988) has made a new forward move. In this sense, investigation of short run macroeconomic problems, long run growth, neoclassical growth models which involved external technologic developments have left its place to new growth theories which contained technological developments as internal.

The beginning of the new growth models were formed on the works of Romer(1986), Lucas(1988), Rebello (1991), Arrow(1962) and Uzawa (1965). These models did not involve technological change. Growth could be infinite in these models since that new kinds of capital were included and that these new factors of production were not handled according to the law of diminishing returns. Rapid spread of information between producers, external utility of human capital, both of which prevented capital accumulation to work according to the diminishing returns, constituted a part of this system. R\&D and imperfect competition were included in growth models by Romer between 1987 and 1990. Besides, Agion and Howitt (1992) and Grossman- Helpmon (1991) have also made significant contributions. In these models the use of R\&D brings forth monopolistic power. If creative information is continuous in an economy, long run growth will always be positive. In these type of models, the reasons of why Pareto optimal disappear is the formation of new goods and new methods of production. Long run growth rate depends on government behavior such as taxation, procurement of legal framework, protection of intellectual opinion rights, regulation of international trade, regulation of financial markets and other sectors of the economy.

New models also undertake spread of technology. These models also include how the technological developments in a developed country are imitated in a follower country. Since that imitation is less costly that achieving technological developments; new conditional convergence is handled similar to the neoclassical approach.

Population growth is another key external parameter in neoclassical models. Rapid population growth decreases level of output per capital and worker. These types of approaches are undertaken in neoclassical models whereas population growth is taken as internal in new models.

The most screaming separation between growth theories of 1960 and 1980-1990 is that empirical relationships that verified theory are given more importance in 1980-1990s. Although some of these empirical works still included conditional convergence, most of them handled new growth theories.

\section{EMPIRICAL WORK}

As it was found that neoclassical growth theory was insufficient in explaining traditional growth factors such as capital and labor force; residual approach gained sovereignty. Then the sources of this residual was tried to be found. There were natural measurement mistakes between these sources. However not all of this residual could have been due to these mistakes. Improvement in the quality of the capital and labor force that provide productivity increases was a result of the science, research and development and technological advances. (Romer, 1997:62). In the near past, a new application, in which regressions are used as intra country cross section study, has been developed. In 
these regressions growth rates of some countries are taken as dependent variable whereas economic and political factors that are considered to influence growth are taken as independent variables. In fact, in a country there are two general approaches for growth analyses. The first approach is the one above that uses intra country cross sections and the second approach tries to decompose the effects of the units of production inputs and the productivity increases caused by these inputs on the growth rate. During the last years, a transition from traditional line to new approaches is observed in the cross section studies. This transition is mainly due to the internal growth models that we name as third wave. In the traditional neoclassical growth theory, it was assumed that diminishing returns affected the use of capital and that savings rate was constant. Therefore, it was concluded that two main factors that determined economic growth were

\section{CROSS-SECTION ANALYSIS}

In the first stdudy, the presence of a significant difference between the growth trends of developed and underdeveloped countries. For this purpose, data of 50 countries is collected. Of these data, 25 are for developed and the other 25 are for underdeveloped countries. The model is formed on the base of a basic neoclassical production and an ampirical work is performed. Here, structural differences between developed and underdeveloped countries are examined by the use of Chow-test methodology. Capital fixed consumption is used in the place of capital and country population is used as a proxy for labor. In the results of the study, a difference due to the proclivity of the growth trend is not observed, however, a diference due to intercept term is found to be present.

As a result of this study, we have observed a difference due to the slope of the growth trend, but there is no difference due to the intercept point.

$\mathrm{Y}=\mathrm{f}(\mathrm{K} 1 \mathrm{~L})$

$\mathrm{GDP}=\beta_{\mathrm{a}}+\mathrm{B}_{1}$ Fixed Capital Consumption $+\beta_{0}$ Population $+\mathrm{U}_{\mathrm{t}}$

In the model, we use dummy variables to represent the structural differences across countries.

Table 1: First Regression Results(All Cross Countries)

\begin{tabular}{|c|c|}
\hline Multiple R-Square & 0.860454 \\
\hline R-Square & 0.74038 \\
\hline Adjusted R-Square & 0.729333 \\
\hline Standard Error & 77891.13 \\
\hline Number of observations & 50 \\
\hline F-test result & $67.01708 \quad$ Significance:( 1.73E-14) \\
\hline
\end{tabular}

Table 2: Second Regression Results

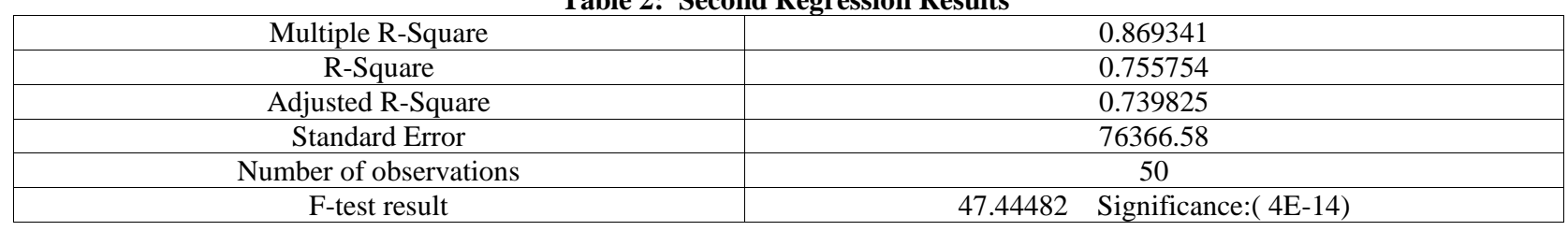

Table 3: Third Regression Results

\begin{tabular}{|c|c|}
\hline Multiple R-Square & 0.869696 \\
\hline R-Square & 0.756371 \\
\hline Adjusted R-Square & 0.728685 \\
\hline Standard Error & 77984.23 \\
\hline Number of observations & 50 \\
\hline F-test result & $27.32043 \quad$ Significance:( 1.82E-12) \\
\hline
\end{tabular}




\section{Test Procedures:}

1. Identical Intercept Test

$\begin{array}{lll}\text { SSE 1: } 47 & 2.85 \mathrm{E}+11 & \text { Table Value: } 4.02 \\ \text { SSE 2: } 46 & 2.68 \mathrm{E}+11 & \\ \text { F: } & 1.69 \mathrm{E}+10 & \underline{2.8953} \\ \text { 5.83E+06 } & & \end{array}$

2. Identical Slope Test

$\begin{array}{llll}\text { SSE 2: } 46 & 2.68 \mathrm{E}+11 & & \\ \text { SSE 3: } 44 & 2.68 \mathrm{E} 11 & & \text { Table Value: } 3.23 \\ \text { F: } & 6.78 \mathrm{E}+08 & 6.08 \mathrm{E}+09 & \underline{0.0557}\end{array}$

3. General Homogenic Test Between The Two Groups

$\begin{array}{lllll}\text { SSE 1: } & 47 & 2.85 \mathrm{E}+11 & & \text { Table Value: } 2.8 \\ \text { SSE 3: } & 44 & 2.68 \mathrm{E}+11 & & \\ \text { F: } & & 176 \mathrm{E}+10 & 6.08 \mathrm{E}+09 & 0.96261 \\ & & 5.85 \mathrm{E}+09 & & \end{array}$

\section{CONCLUSION}

We can summarize the outcomes of this test procedure as follows. The F-value of 46.1 is tested under a 0.05 significance level. The null hypothesis is rejected for the first test, whereas the null hypothesis is do not rejected for the third model. These show that there is no difference between the slopes but that the change stems from the intercept points. The slope differences grow out of the second test. The first test constitutes the difference between the intercept points. The generally acceptable outcome of this empirircal study signals for a structural difference between the developed and underdeveloped countries.

\section{TIME SERIES ANALYSIS}

In this study we investigate the causality between the productivity and economic growth. We look for an answer to the question that asks if the reason behind the long term high growth rate of Turkey, between the they years 1988-1997, is indeed productivity?

\section{Model And Data} below:

The econometric analysis is performed under a Cobb-Douglas type neoclassical growth model as formulated

$$
\mathrm{Yt}=\mathrm{K}_{\mathrm{t}}^{\alpha} \mathrm{Lt}^{1-\alpha} \quad 0<\alpha<1
$$

And the logarithmic form of this model is:

$\log \mathrm{y}_{\mathrm{t}}=\alpha \log (\mathrm{K} / \mathrm{L}) \mathrm{t}+\log \mathrm{Lt}$

The following equation is simply the linear stochastic model:

$$
\tilde{\mathrm{y}} \mathrm{t}=\alpha_{0}+\alpha_{1} \tilde{\mathrm{k}}_{\mathrm{t}}+\sum_{\mathrm{t}}
$$


Here,

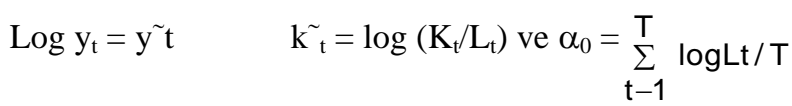

The appropriate data for this model are in the form of three-month time series for 1988:2 - 1997:4.

The series $(\mathrm{K} / \mathrm{L})_{\mathrm{t}}$ is produced based on the following dynamic model:

$\Delta \mathrm{K}_{\mathrm{t}}=\mathrm{I}_{\mathrm{t}}-\delta \mathrm{K}_{\mathrm{t}}$

$\mathrm{I}_{\mathrm{t}}=$ investment stock

$\mathrm{K}_{\mathrm{t}}=$ capital stock

$\mathrm{I}_{\mathrm{t}}=\mathrm{s} \mathrm{Y}_{\mathrm{t}} \quad\left(\mathrm{Y}_{\mathrm{t}}=\mathrm{GNP}\right)$

Here, $\delta=0.025$

\section{Econometric Approach}

The time series specifications of the series are investigated and the conditions in which they are stationary are summarized, according to the ADF approach, in the table below.

Here,

$$
\begin{aligned}
\operatorname{DGNP}_{\mathrm{t}}=\log \tilde{\mathrm{y}}_{\mathrm{t}}-\log \tilde{\mathrm{y}}_{\mathrm{t}-1} \\
\text { D PROD }_{\mathrm{t}}=\tilde{\mathrm{k}} \mathrm{t}-\tilde{\mathrm{k}}_{\mathrm{t}-1}
\end{aligned}
$$

And,

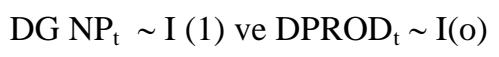

In other words, $\mathrm{GNP}_{\mathrm{t}}$ or $\mathrm{y}_{\mathrm{t}}$ is found to be stationary in its first differences and $\operatorname{prod}_{\mathrm{t}}=(\mathrm{K} / \mathrm{L})_{\mathrm{t}}$ is stationary in its level. As a result of these tests, the stationary series are added to the analysis through the Granger's causality procedure.

Firstly, the appropriate lag structure for the VAR model is determined by using the AIC and SC criterias as given below:

\begin{tabular}{|c|c|c|}
\hline La & SC & AIC \\
\hline 8 & 0,309 & $-1,308$ \\
\hline 7 & 7,450 & $-0,960$ \\
\hline 6 & 8,080 & $-1,130$ \\
\hline 5 & $-0,222$ & $-1,240$ \\
\hline 4 & $-0,593$ & $-1,418$ \\
\hline 3 & $-0,105$ & $-0,740$ \\
\hline 2 & $-0,060$ & $-0,513$ \\
\hline 1 & $-0,400$ & $-0,667$ \\
\hline * Are Maksimum Values & & \\
\hline
\end{tabular}


The appropriate lag length is found to be 4 . In the light of the statistical analysis above, we can think that the model below reflects a suitable growth model:

$$
\begin{aligned}
& \operatorname{DDGNP}_{\mathrm{t}}=\alpha_{0}+\sum_{\mathrm{i}=1}^{4} \beta i \operatorname{DPROD}_{\mathrm{t}-\mathrm{i}}+\sum_{\mathrm{i}=1}^{4} \phi_{\mathrm{i}} \operatorname{DDGNP}_{\mathrm{t}-\mathrm{i}}+\sum_{i \mathrm{t}} \\
& \operatorname{DPROD}_{\mathrm{t}-\mathrm{i}}=\alpha_{1}+\sum_{\mathrm{i}=1}^{4} \Psi_{\mathrm{i}} \operatorname{DDGNP}_{\mathrm{t}}+\sum_{\mathrm{i}=1}^{4} \mathrm{k}_{\mathrm{i}} \operatorname{DPROD}_{\mathrm{t}-\mathrm{i}}+\sum_{2 \mathrm{t}}
\end{aligned}
$$

The Hypotheses According To Granger Causality Test Can Be As:

\begin{tabular}{|ll|}
\hline $\mathrm{H}_{0}: \Psi_{\mathbf{i}}=0$ & (Growth is not the cause of productivity.) \\
$\mathrm{H}_{1}: \Psi_{\mathbf{i}} \neq 0$ & (Growth is the cause of productivity.) \\
The other one is: & \\
$\tilde{\mathrm{H}}_{0}: \beta_{\mathrm{i}}=0$ & (Productivity is not the cause of growth.) \\
$\tilde{\mathrm{H}}_{1}: \beta_{\mathbf{i}} \neq 0$ & (Productivity is the cause of growth.) \\
Calculated $\mathrm{F}=6.737$ & and $\mathrm{Pr}=0.00096$ \\
\hline
\end{tabular}

$\sim$

As a result, $\mathrm{H}_{\mathrm{o}}$ and $\mathrm{H}_{\mathrm{o}}$ hypotheses are rejected. In other words; there exists the following relationship:

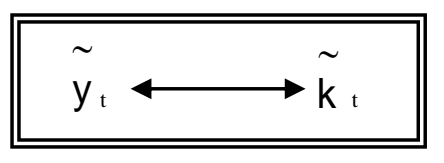

That means that productivity and economic growth do support each other in Turkey.

\section{PANEL-DATA ANALYSIS}

In this part we will give an example of panel data analysis which will help us interpret the relation between growth and inflation across countries. While processing this analysis we will include different variables in order to see whether they will have significant effects on this relation. One of the most interesting research areas in the macroeconomics is the relationship between inflation and growth. However, there is no single theory for inflation and economic growth in the literature, and the empirical evidence is scant and mixed.

Two different views, namely structuralist and monetarist, dominate economic literature with respect to the relationship between inflation rate and economic growth. The monetarists assert that price stability is a prerequisite for economic growth, claiming that inflation causes some distortions, and through these distortions, retards growth. In the structuralist view, on the other hand, wage adjustments lag behind price adjustments, changing the income distribution in favor of capitalists. Making the Kaldorian assumption that the capitalists have a higher propensity to save, this income redistribution will increase total savings, total investment, and consequently economic growth. Meanwhile, some economists remain skeptical, arguing that a nominal variable can not affect a real one.

One of the main methods of estimating the effect of inflation on growth is to use cross-country data. However, statistical tests on the direction of causation cannot be applied to cross-sectional data. One of the earliest cross-sectional studies was by Kormendi and Meguire (1985). Using data for 47 countries over the 1950-77 period and a wide set of explanatory variables - each averaged over six-year periods - they found that inflation had a 
significant negative correlation with output growth, apparently because of the negative association between inflation and investment. Their results suggested that one percentage point higher inflation was associated with a half-point reduction in the annual growth rate. Grier and Tullock (1989) used pooled time series (five-year averages) and crosssectional data between 1951 and 1980 for 113 countries to assess the impact of a range of variables on real output growth. They found that a single empirical model could not explain differences in growth among these countries and therefore presented different results for different country groups. For OECD countries, they found strong negative correlations between growth and the share of government spending in national income, and between growth and the variability of inflation, but no significant relation between growth and inflation. Elsewhere, the only significant relation between inflation and growth was a negative association in the African countries; and inflation variability had a significant negative relation with growth in the Asian countries. De Gregorio $(1992,1993)$ used cross-sectional data for 12 Latin American countries to test the implications of an endogenous growth model in which the level and efficiency of investment are related negatively to the rate of inflation. He found that both inflation and its variance were negatively correlated with growth; the effect appeared to arise mainly because of a reduction in the efficiency of investment. His results suggested that a halving of the inflation rate in these countries between 1950 and 1985-from $34 \%$ to $17 \%$ might have increased their annual growth rates by half a percentage point. However, he used only a limited set of third variable. Researchers commonly cite supply shocks as a candidate for this, in particular the oil price shock in the early 1970s which lowered growth and raised inflation inmost countries. Some attempts have been made to allow for this by including terms of trade changes in the estimated equations but this may not be an adequate proxy for all supply shocks. Fischer, concluded that 'since the inflation rate is not an exogenous variable to the economy, there is some logical difficulty in discussing the costs of inflation per se rather than the costs and benefits of alternative policy choices'. Such considerations have led a number of commentators to express scepticism about the value of empirical work on inflation and growth (and indeed about tests of the determinants of growth generally). For example, Solow (1994) commented that although various political-economic factors 'might easily affect the growth rate if the growth rate were easily affected I do not find this a confidence-inspiring project. It seems altogether too vulnerable to bias from omitted variables, to reverse causation, and above all to the recurrent suspicion that the experiences of very different national economies are not to be explained as if they represented different points on some well defined surface. The introduction of a wide range of explanatory variables has the advantage of offering partial shelter from the bias due to omitted variables. But this protection is paid for. As the range of explanation broadens, it becomes harder and harder to believe in an underlying structural, reversible relation. However, this scepticism may itself be overdone. Despite a number of shortcomings, the available evidence provides support for a negative relationship between inflation and growth, consistent with the predictions of the theoretical literature. But it would be still more convincing if a structured, micro-level testing of the hypotheses generated by the economic theory of the costs of inflation could be undertaken - and if this confirmed the negative relationship between inflation and growth.

Economic theory suggests that inflation imposes costs on the economy through a variety of channels. And although the empirical evidence cannot be regarded as conclusive, it is broadly consistent with the theoretical results. This implies that there are advantages in achieving and maintaining price stability, even if these are difficult to quantify precisely.

In our study, we will test if the inflation has a negative effect on countries growth rate. While processing our study, we improve our analysis by using structural break test (Chow metodology). In the first empirical test part (cross section analysis part) we impose structural break test inorder to test if there is a structural change between developed and under developed countries. The test results suggest that there is a significant difference between developed and underdeveloped countires growth process. So we use this result inorder to improve our panel data analysis estimation results. By the help of this classification, we grouped countries and run the panel data analysis for this two different group, as we can name them developed and under developed. So we try to improve our estimation results. We choose the same set of countries for panel data analysis and cross section analysis. So we combine two different type of analysis by using the result of cross section analysis. We take the data from World Bank Development Index: 2005 world development indicators online. They are indexed to 1986. Before we process the ampirical analysis we calculate the growth rates of each variable ${ }^{1}$.

\footnotetext{
${ }^{1}$ First we take the logarithm of all variables and then take the first difference. So we obtain mountly growth rates of all data.
} 
The model we use in panel data analysis is:

$$
G r w_{i, t}=\beta_{0}+\beta_{1} \pi_{i, t}+\beta_{2} K_{i, t}+\beta_{3} L_{i, t}+\beta_{4} C a b_{i, t}+\varepsilon_{i, t}
$$

Dependent Variable: GDP

\begin{tabular}{|l|l|l|l|}
\hline GDP(grw) & Panel Data All Countries (1) & Panel Data Developed C.(2) & Panel Data Underdeveloped (3) \\
\hline Constant & 0.000002 & 0.000004 & 0.000002 \\
& $(5.33)$ & $(3.32)$ & $(4.04)$ \\
\hline Inflation(grw) & -0.4655229 & -0.4716174 & -0.0019641 \\
& $(-2.38)$ & $(-4.06)$ & $(-0.02)$ \\
\hline Capital(grw) & 0.0701163 & 0.0237446 & 0.1339138 \\
& $(2.72)$ & $(1.31)$ & $(4.30)$ \\
\hline Labor(grw) & 0.5012994 & 0.4506786 & 0.2346007 \\
& $(6.020)$ & $(1.90)$ & $(1.86)$ \\
\hline Cab(grw) & -0.1407604 & -0.0940078 & 0.0210243 \\
& $(-4.61)$ & $(-1.14)$ & $(0.70)$ \\
\hline
\end{tabular}

As seen from the above table, inflation has a significant negative effect on growth. However, the level of this significance tends to diminish in underdeveloped countries, whereas in the developed countries there is an increase in the significance level of the negative effect of inflation on growth. The results that we have obtained seem to be controversial. While the regression containing all countries present consistent results with the theory that argues for a strong negative relationship between inflation and growth, the regressions for each of the developed and underdeveloped subgroups yield quite weaker relationships between the growth and inflation.

We also included the capital account balance in our model as an explanatory variable in order to get more accurate and valid results. This purpose of us was held in the first regression containing all countries, where there came out a strong negative relationship between the capital account balance and growth. On the other hand, this link as the inflation and growth relationship has also weakened when we conducted separate regressions for each developed and underdeveloped subgroups. Furthermore, the relationship even turned to a weak but positive relationship for the underdeveloped subgroup.

Overall, the regression outcomes presented in the table above imply that all explanatory relationships tend to become less significant when we apply individual regressions to each group of countries. We argue that this controversy in the results may be due to the fact that the with-in group differences decrease the strength of the expected relationships. Whereas, these differences are neutralized, therefore yield more accurate and significant relationships as we regress the countries altogether.

For this purpose, in order to test if these effects of grouping do matter a lot, we tried a pooling approach in which we pooled first all countries together, and then pooled the developed countries and finally the underdeveloped countries. Then we checked the R-square values for each of the three pooled regressions. We found out that the grouping effect is also present in these regressions. The R-square for all country regression pooled regression is $30 \%$, whereas it is $32 \%$ for developing countries and $27 \%$ for underdeveloped countries. The pooled regression analysis show that developed countries have more regular relationships between these variables, and each of the underdeveloped and developed groups pooled regressions have less regular relationships where the relationships become even less regular in the underdeveloped subgroup.

To sum up, this study is consistent with the previous literature and has showed that it requires more explanatory variables to improve the model and achieve more conclusive results. Besides, more developed econometric techniques should be used for the decomposition of different subgroups. Country-specific studies should be done and used for gathering more homogenous groups. By homogeneous groups, we mean similarities in 
economic, political, institutional, infrastructure etc conditions. If we better homogenize the data, we can reach more valid and consistent relationships even with a small number of variables. This idea can be a contribution to the previous literature on growth theory. Furthermore, the significant negative effects of inflation on growth that we have found out can also be named as a small contribution to the relevant theory.

\section{GENERAL CONCLUSION}

We mainly based our study on a recent paper called as "The New Growth Evidence" which was written out by J. Temple (2000) who gives a very detailed discussion of the empirical issues concerning the growth literature. In this work we have not only gave his paper's brief summary but also pointed out the borders of growth theory with a number of specific examples of empirical studies in growth literature. In this respect, we organized three types of empirical analysis which are achieved by different estimation procedures. In the first example, we deal with cross country evidence in which we aimed to point out the growth differences between developed and underdeveloped countries. In order to show these differences we gathered data about fifty countries and made cross section analysis in between. We then used Chow methodology to pinpoint the structural break between developed and underdeveloped countries. In the second example, we provided a time series analysis of one country, in which we intended to find out whether a country's productivity level does or does not affect the GNP growth rate. This analysis constructed with the Turkish data and we found out that productivity has a significant effect on growth process. Last and the third example was given from a panel data analysis, in which we took the same sample countries as of the cross section analysis. The rationale was to pool all the countries at first and observe the existence of any regularity and later to apply panel data analysis to each group of country -namely developed and underdeveloped- by the help of cross section analysis. Overall, the purpose of this empirical study is to show robustness of the empirical regularities in the homogeneous type countries. And making homogeneous countries group, there will exists more regular relations. In conclusion, the paper gave brief summaries of theoretical and empirical issues which covered the boundaries of discussions and more importantly all the main types of empirical studies.

\section{REFERENCES}

1. $\quad$ Acar, Y. (2002) İktisadi Büyüme ve Büyüme Modelleri Bursa: Uludağ Üniversitesi Güçlendirme Vakfi Yayın No: 191.

2. Agion, P. And Peter H. (1992) A model of Growth through Creative Destruction, Econometrica, 60, (March), 323-351.

3. $\quad$ Akyüz, Y. (1977) Sermaye Bölüşüm Büyüme Ankara: Ankara Üniversitesi Basımevi Yayın No : 400.

4. Arrow, K. (1962) The Economic Implications of Learning by Doing, Review of Economic Studies, 29 (June):155-173.

5. Barro, R. J. (1996), Determinants of economic growth: a cross-country empirical study, NBER Working Paper: 5698.

6. $\quad$ Barro, R.J., Martin, X.S. (1993) Economic Growth New York: McGraw-Hill

7. Bulutay, T. (1995) Yeni Büyüme Kuramları ve Büyüme, Kalkınma Konusunda Diğer Bazı Yaklaşımlar DPT: ISBN 975-19-0986-4.

8. Bruno, M. and Easterly, W. (1998), Inflation crises and long-run growth, Journal of Monetary Economics, 41(1), February, 3-26.

9. Cass, D., (1965) Optimum Growth in an Aggregative Model of Capital Accumulation. Review of Economic Studies, 32 (July), 233-240.

10. De Gregorio, J. (1992), The effects of inflation on economic growth, European Economic Review, 36, 417 24.

11. De Gregorio, J. (1993), Inflation, taxation and long-run growth, Journal of Monetary Economics, 31, 271-98.

12. Domar, E. D., (1946) Capital Expansion, Rate of Growth, and Employment, Econometrica, 14 (April), 137 147.

13. Grier, K. B. and Tullock, G. (1989), An Empirical analysis of cross-national economic growth, Journal of Monetary Economics, 24, pages 259-279.

14. Grimes, A. (1991), The effects of inflation on growth: some international evidence Weltwirtschaftliches Archiv, 127, pages 631-644. 
15. Gylfason, T. and Herbertsson, T. T. (1996), Does inflation matter for growth? CEPR discussion paper no. 1503.

16. Harrod, R.F. (1939) An Essay in Dynamic Theory, Economic Journal, 49(June), 14-33.

17. Jones, I. J. (1998) Iktisadi Büyümeye Giriş New York : W.W. Norton;

18. Kormendi, R. C. and Meguire, P. G. (1985), Macroeconomic determinants of growth: cross-country evidence, Journal of Monetary Economics, 16, pages 141-63.

19. McTaggart, D. (1992), The cost of inflation in Australia; in Inflation, Disinflation and Monetary Policy, Reserve Bank of Australia.

20. Pack, H. Endogenous, Growth Theory: Intellectual Appeal and Ampirical Shortcomings, Economic Perspective, 8:55-72; 1994.

21. Rebello, S. (1991) Long-run Policy Analysis and Long-run Growth, Journal of Political Economy, 93,(June), 500-521.

22. Romer, O. (1996) Advanced Macroeconomics New York: Mc Graw - Hill.

23. Romer, P. M. (1986) Increasing Returns on Long-run Growth, Journal of Political Economy, 14 (October), 1002-1037.

24. Romer, P. (1994) The Origins of Endogenous Growth Economic Perpective , 8:3-23.

25. Sheshinski, E. (1967) Optimal Accumulation with Learning by Doing, in Karl Shell, ed., Essays on the Theory of Optimal Economic Growth, Cambridge MA, MIT Press, 31-52.

26. Solow, R. M. (1994) Perpectives on Growth Theory Economic Perspective, 8 : 45-55.

27. Temple, J. (1999)The New Growth Evidence, Journal of Economic Literature, 112-156.

28. Williamson, T. (1999) Notes on Macroeconomic Theory Iowa: Iovo Unversity.

29. Uzawa, H. (1965) Optimal Technical Change in an Aggregative Model of Economic Growth, International Economic Review. (January), 18-31. 


\section{NOTES}

